\title{
The Influence of Pulse Shape on the Performance of a Mixed Flow Turbine for Turbocharger Applications
}

\author{
S. P. Lee, A. Rezk and M. L. Jupp \\ Turbocharger Research Institute, University of Huddersfield, \\ Huddersfield, United Kingdom \\ Email: sam.lee@hud.ac.uk \\ A. K. Nickson \\ BorgWarner Turbo Systems, Bradford, United Kingdom
}

\begin{abstract}
Engine downsizing allows automotive manufactures to achieve improved efficiency and reduce emissions. Turbocharging can increase the power density of the engine, and therefore plays a vital role in downsizing. Due to the nature of the reciprocating engine, a turbocharger turbine operates in a highly unsteady environment. This paper presents a computational investigation looking at the impact of pulse shape on the performance of a mixed flow turbine for turbocharger applications. While the impact of pulse frequency and amplitude on turbine unsteady performance has received significant attention in the past, little work has been done on the impact of the pulse shape. In the current study, four inlet pulse shapes have been investigated and shown to have a significant impact on turbine instantaneous performance, where efficiency and mass flow hysteresis varied significantly between test cases. This result shows for in-depth analyses of turbine flow physics and loss mechanisms, accurately modelling the inlet pulse shape is vital. The square pulse showed the most distinct impact with normalized cycle average efficiency decreasing by $1.37 \%$ and a $2.23 \%$ reduction in normalized stage MFP when compared to the sinusoidal wave. The variation in normalized cycle averaged stage efficiency was found to be less than $0.25 \%$ for the remaining three wave forms and the variation in normalized cycle averaged MFP less than $0.5 \%$. This finding suggests that a simple sinusoidal wave form can be used for the majority of cycle-averaged performance comparisons.
\end{abstract}

Index Terms - Pulsating Turbine Flow, CFD, Pulse shape.

Manuscript received - 10/3/2017, Revised - 20/4/2017

\section{INTRODUCTION}

Engine downsizing is becoming increasingly common in the automotive sector in a bid for greater engine efficiency and lower emissions. As a result, turbocharging is widely used to increase engine power density. This is achieved by extracting exhaust gas energy using a turbine to drive a compressor that increases the engine intake air density. Due to the nature of the reciprocating engine, the turbine operates under highly pulsating conditions presenting significant design challenges for turbocharger manufacturers.

The first published example of an experimental pulsating flow investigation was conducted by Wallace and Blair [1]. The authors investigated the effects of pulse frequency, pulse form, pulse amplitude, turbine speed, nozzle angle, pipe length, and pipe area. As noted by Newton [2] this large undertaking of work resulted in no solid conclusions. Later, the effect of pulse frequency, amplitude and shape were investigated by Benson and Scrimshaw [3], Kosuge et. al [4] and Benson [5] respectively. However, these studies lacked consistency and no conclusive trends were found. Despite the lack of conclusive results, Benson [5] defined pulse shape in terms of an inlet form factor which was given as the RMS value of the pulse pressure divided by the mean. He observed that the pulse form had an impact on turbine performance.

In 1986 Dale and Watson [6] published the first work completed on the pulsed flow test rig at Imperial College London. This facility provided instantaneous measurements of rotor torque and mass flow, resulting in more realistic results and for the first time showing the hysteresis in turbine performance. This work was a significant step forward as the true unsteady performance of pulsating turbine flow was captured. 
Since then, a significant amount of work has been completed in characterizing unsteady flow in turbines, both experimentally and computationally. While the impact of pulse frequency and amplitude on turbine performance has been investigated by a number of authors [7-9], a range of approaches for modelling the shape of the turbine inlet pulse are seen in the literature. Galindo et. al [10] and Lee et. al [11] used a sinusoidal wave form. Galindo et. al stated that as the inlet pressure pulse can be decomposed into a sum of sinusoidal wave forms (as demonstrated by Costall and Martinez-Botas [12]), therefore the turbine behavior under a sinusoidal pulse is of particular importance. Alternately, Roclawski et al. [13] and Hellstrom and Fuchs [14] simulated turbine operation using inlet pulses generated from one dimensional engine simulation tools. Yang et al. [15] and Padzillah et al. [8] used the pulse form generated from experimental test facilities using a chopper plate and therefore had extensive experimental validation for the computational method used. The pulse shape generated from a chopper plate is not necessarily representative of that found on engine. In reality, the turbine inlet pulse is dependent on the exhaust manifold geometry, valve and injection timing and operating conditions and is therefore very difficult to fully characterize. Furthermore, as stated by Hakeem et al. [16], achieving independent control of pulse shape and frequency is very difficult experimentally hence limiting the ability to experimental investigate the impact of pulse shape.

It is important for turbocharger manufacturers to understand the impact of pulse shape on performance due to the difficulty of obtaining real engine pulses. This paper investigates the impact of different inlet mass flow pulse shapes on turbine performance. The total mass flow over the pulse cycle is constant in all cases and the impact on instantaneous and cycle-averaged performance is investigated.

\section{COMPUTATIONAL APPROACH}

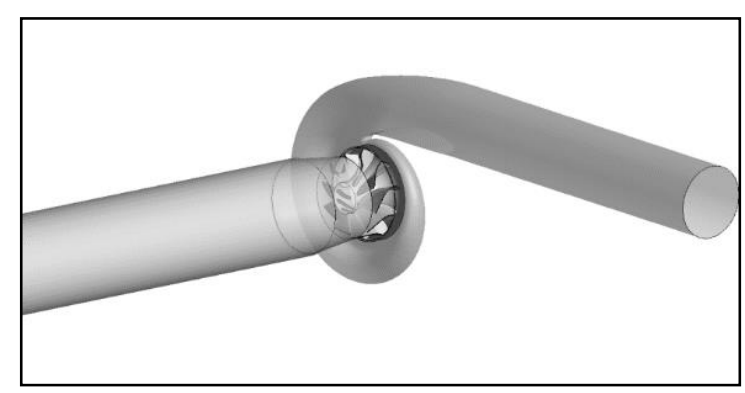

Figure 1 - Computational Domain Set-Up

Figure 1 shows the computational set-up which consists of three domains, the volute, the rotor and the outlet. A full domain specific mesh study was completed similar to that recommended by Galindo et al. [17]. This was extended to include a boundary mesh independence study. The volute and outlet regions contain an unstructured tetrahedral mesh developed in ICEM CFD. The rotor region uses a structured hexahedral mesh completed in ANSYS TurboGrid. All CFD simulations were completed in
CFX 15 using the Shear Stress Transport (SST) turbulence model, and the frozen rotor approach to account for the turbine rotation, which was validated by Aymanns et al. [18].

The computational approach was validated by steady state gas stand test results for the mixed flow rotor used throughout this study. Figures 2 and 3 present the efficiency and Mass Flow Parameter (MFP) from the steady flow hot gas stand testing and computational approach. The definition of MFP is given in Equation 1 where $\dot{m}$ is the stage inlet mass flow, $T_{01}$ is stage inlet total temperature and $P_{01}$ is stage inlet total pressure.

$$
M F P=\frac{\dot{m} \cdot \sqrt{T_{01}}}{P_{01}}
$$

It is clear that the computational results replicate the efficiency characteristics, however, the simulation model substantially over predicts the stage efficiencies and under predicts the stage MFP. This discrepancy can be attributed to the adiabatic assumption of the computational approach as shown by Zimmermann [19].

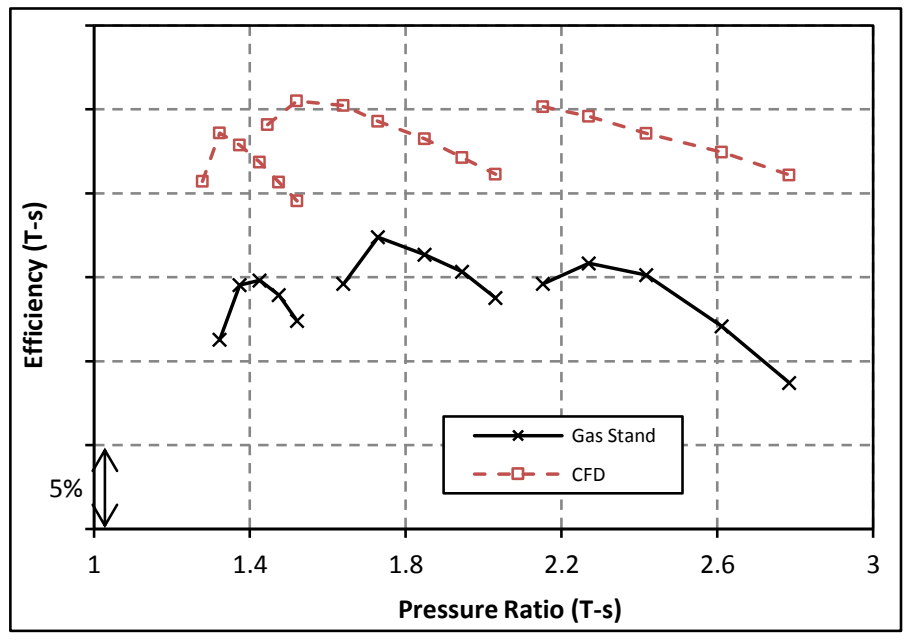

Figure 2: Comparison of Steady State CFD and Gas Stand Efficiency (T-s)

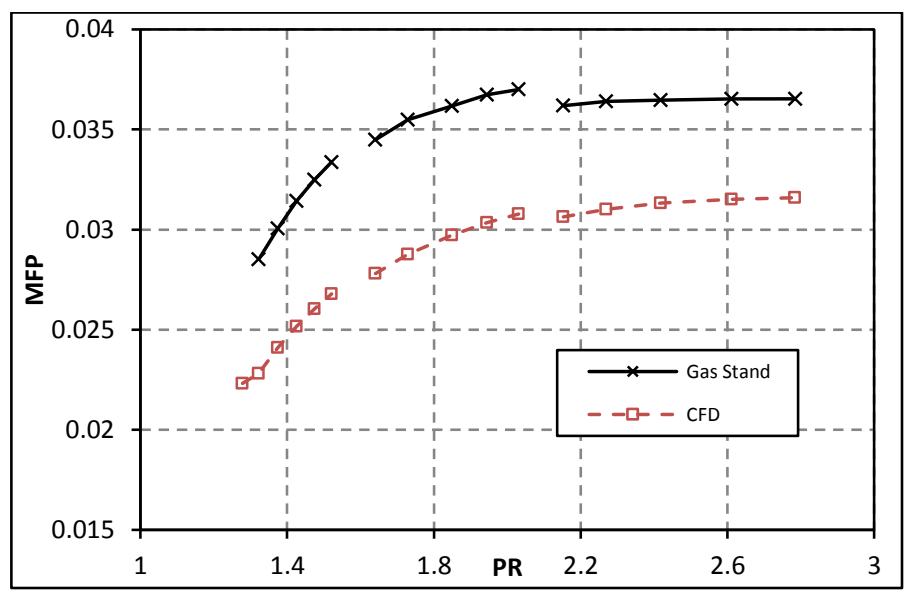

Figure 3: Comparison of Steady State CFD and Gas Stand MFP 


\section{BOUNDARY CONDITIONS}

The inlet mass flow pulse shapes used in the current work are presented in Figure 4. In all cases the integration of the mass flow over the pulse remains the same and the inlet Total Temperature is kept constant at $923 \mathrm{~K}$.

The inlet wave forms implemented include sinusoidal, triangular and square wave forms, as well as a pulse shape that was determined by a one dimensional engine model using a similar approach to Roclawski et al. [13] and Hellstrom and Fuchs [14], and is considered to be a 'realistic' wave form.

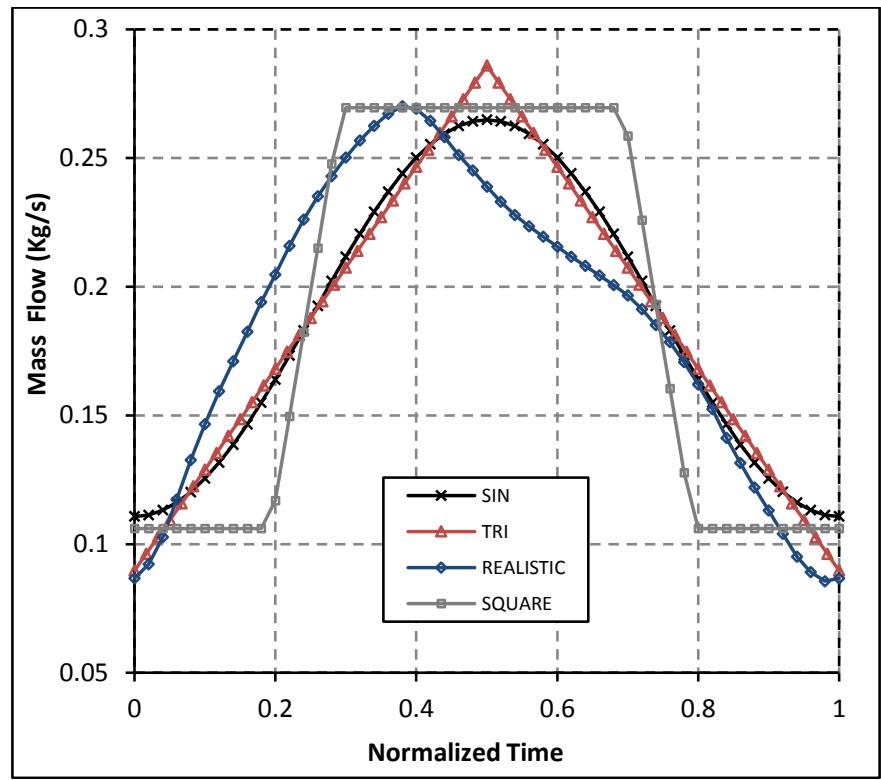

Figure 4 - Inlet Mass Flow Pulses Shapes

As shown by Costall and Martinez-Botas [12] any pulse wave form can be decomposed into a series of sinusoidal waves. As such the realistic wave used in this work can be decomposed through a Fourier transform and its harmonics found. From this data the pulse can be recreated from a specified number of harmonics resulting in a simplified wave. Figure 5 shows the full 'realistic' wave, its fundamental harmonic, the wave formed by its first two harmonics, and the wave formed by its first three harmonics for comparison. It is clear that the realistic wave is not accurately represented until the third harmonic is included. Furthermore, the simple first harmonic fundamental is the same as the sinusoidal wave included in this study. This allows comparison to be made between a significantly simplified pulse shape and that of a more realistic shape. Both the triangular and square waves can be created in the same way and are formed through sums of odd harmonics.

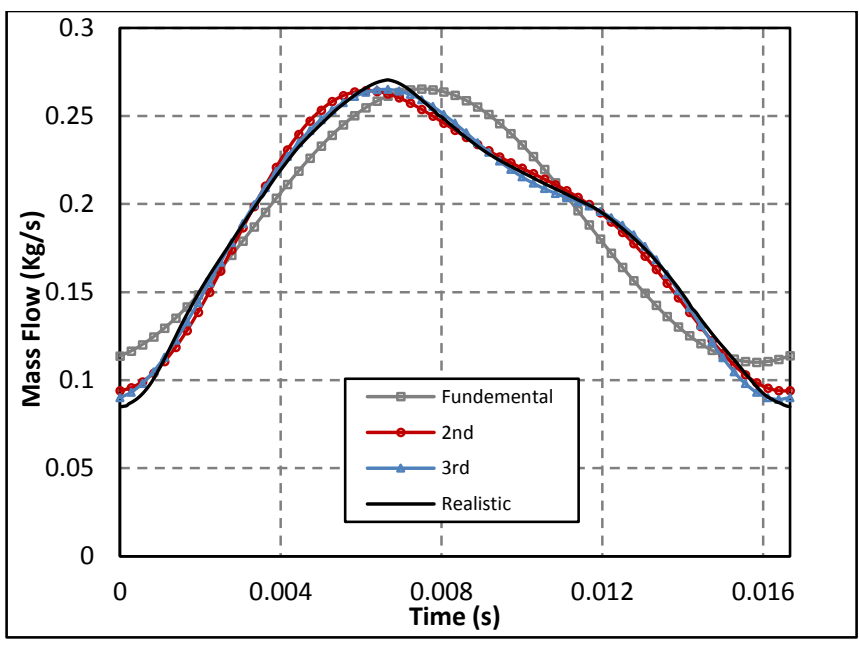

Figure 5 - Realistic Wave Form and it Simplified Pulses.

\section{RESULTS AND DISCUSSION}

The impact of the inlet pulse on the unsteadiness within the volute can be assessed from the mass accumulation. The definition of which is given in equation 2 .

$$
M_{a c c}=\frac{\dot{m}_{1}-\dot{m}_{2}}{\dot{m}_{\text {mean }}}
$$

Where $\dot{m}_{1}$ is the mass flow at the volute inlet, $m_{1.5}$ is mass flow at the volute exit and $\dot{m}_{\text {mean }}$ is the pulse mean mass flow. Greater mass accumulation within the system results in further deviation from quasi-steady performance. Conversely, the relatively small volume of the rotor region has been shown by a number of authors to behave in a quasi-steady manor $[2,13]$. Figure 6 shows the mass accumulation within the turbine volute for the four pulse shapes tested. It is clear that the square wave results in significantly greater accumulation. This effect can be explained by the pulse duty cycles parameter introduced by Szymko [20]. This parameter suggests that the pulse frequency should be taken only over the pulse event. In this case, the square wave would be said to have a frequency of nearly twice that of the other pulse shapes. The remaining three pulse shapes also show a variation in the filling and emptying characteristics. It is clear that the inlet pulse gradient has a significant effect on the filling and emptying of the volute. 


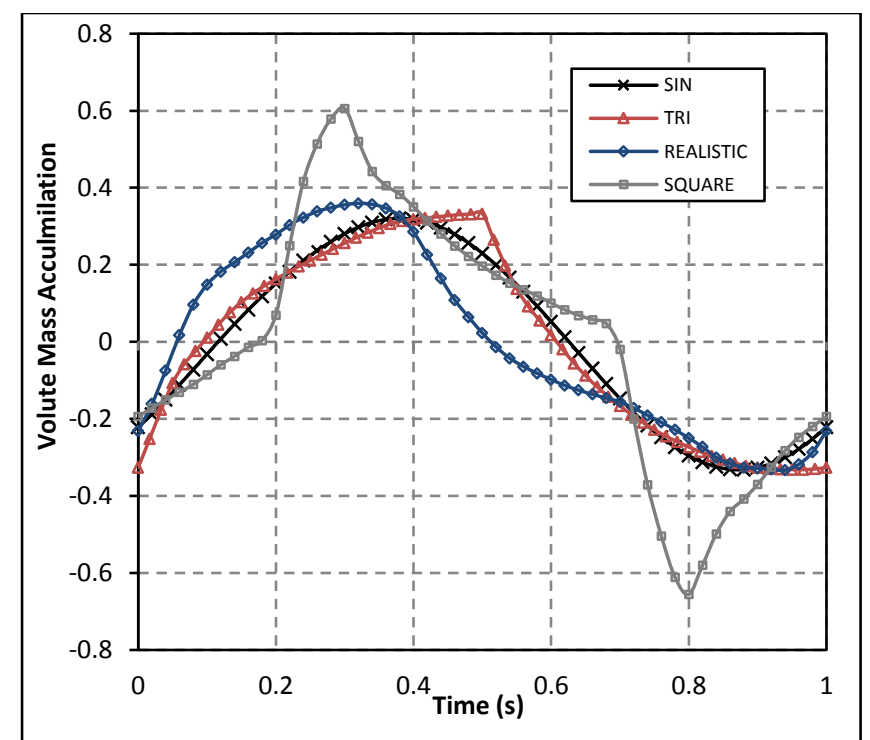

Figure 6 - Volute Mass Accumulation Resulting from the Four Tested Inlet Pulse Shapes

Figures 7, 8, 9 and 10 show the turbine inlet mass flow pulse and the mass flow pulse at the rotor inlet for the sinusoidal, triangle, realistic and square pulse shapes respectively. The sinusoidal wave form shows a phase shift in the peak mass flow and a damping of the pulse amplitude, but the pulse shape is maintained. Both the triangular and realistic waves also see a shifting and damping of the wave amplitude. Furthermore, both pulses exhibit a significant shape change through the volute passage, becoming more sinusoidal in nature. The square wave experiences a significant change in shape as it passes through the volute but with less damping of the peak pulse amplitude. It can be seen from Figure 10 that the step change in mass flow is not present at the rotor inlet. Instead the mass flow increases gradually over approximately $40 \%$ of the pulse time.

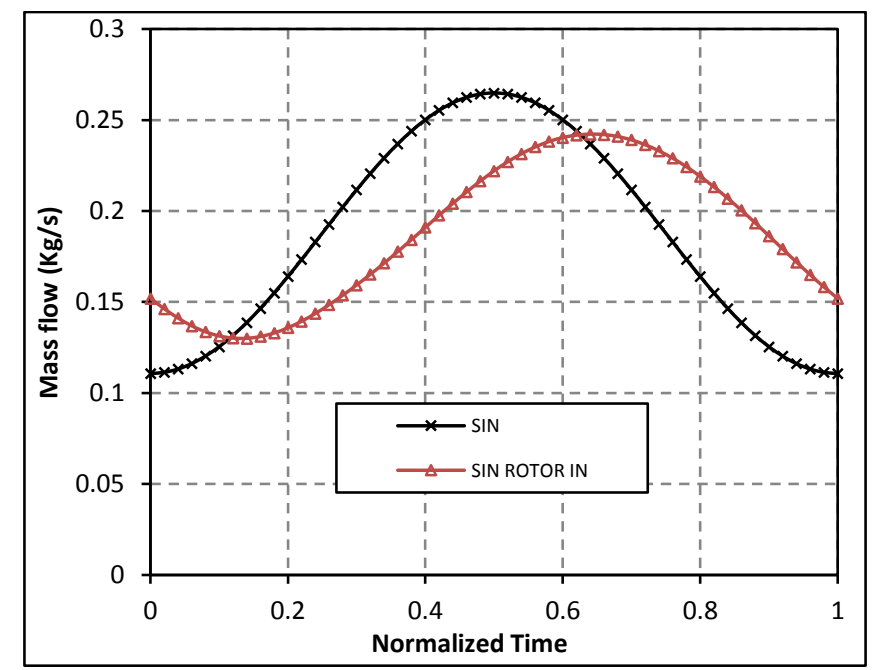

Figure 7 - Sinusoidal Turbine Inlet Pulse and Corresponding Rotor Inlet Pulse

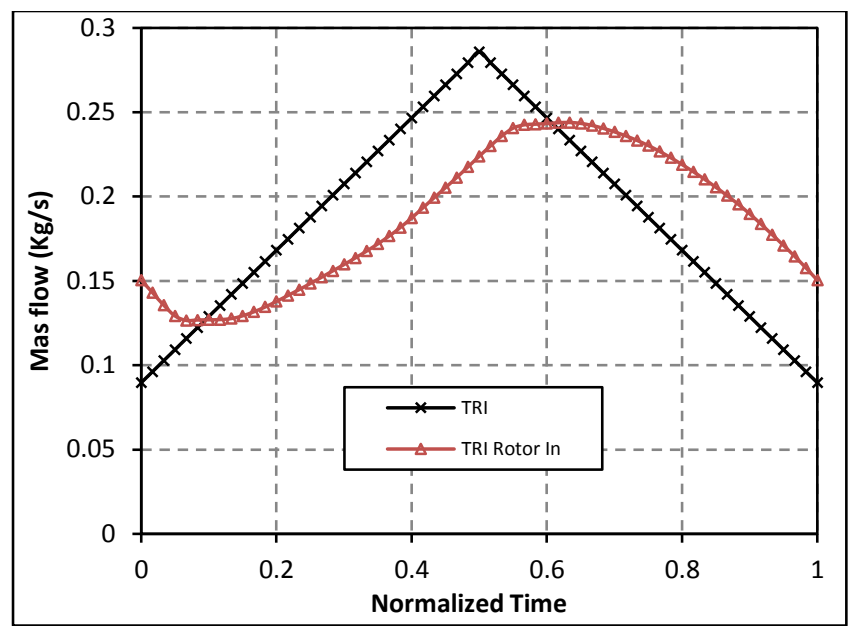

Figure 8 - Triangular Turbine Inlet Pulse and Corresponding Rotor Inlet Pulse

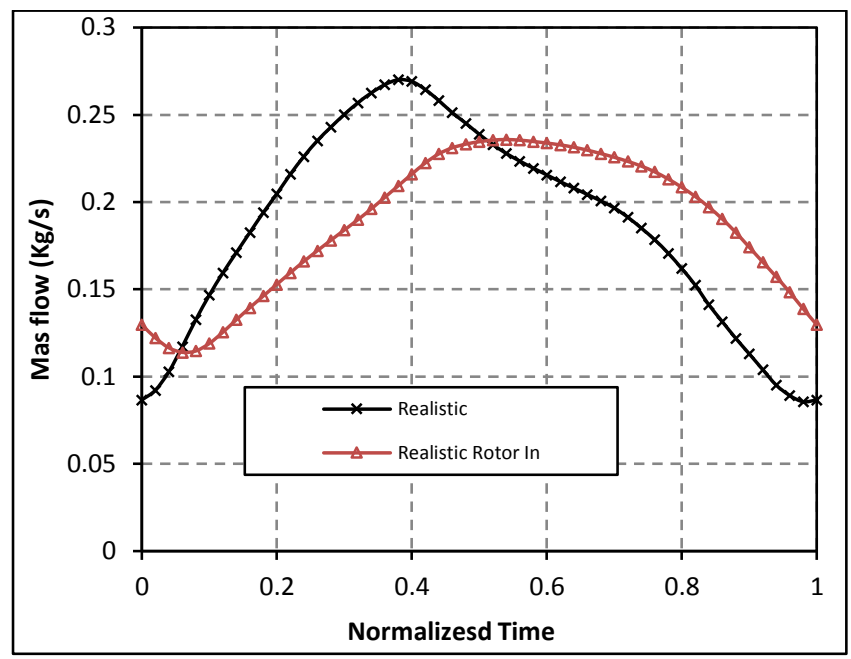

Figure 9 - Realistic Turbine Inlet Pulse and Corresponding Rotor Inlet Pulse

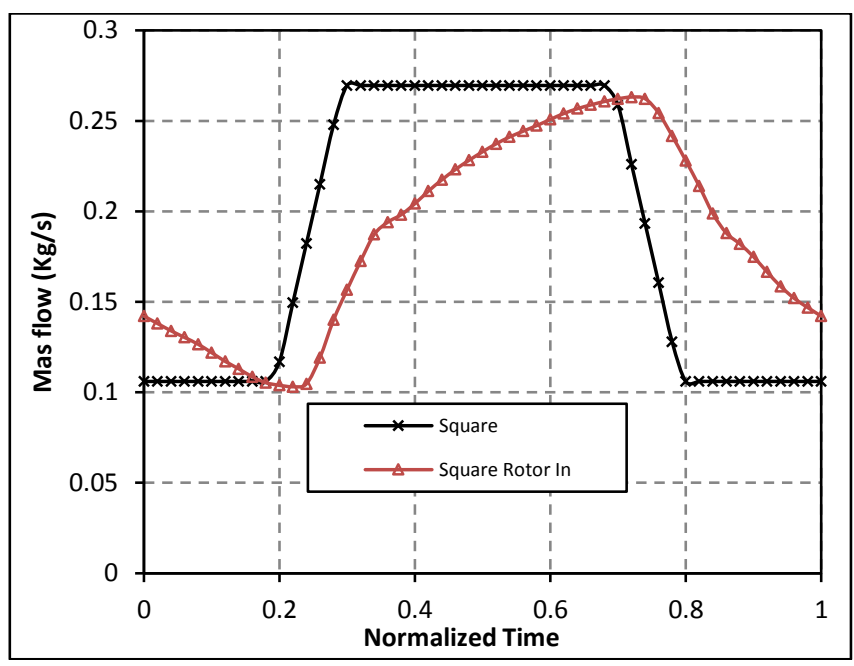

Figure 10 - Square Turbine Inlet Pulse and Corresponding Rotor Inlet Pulse 
The impact of the rotor input pulses can be seen in the rotor torque presented in Figure 11. In all cases, the variation in rotor torque over the pulse cycle is similar in shape to the variation in mass flow at the rotor inlet. The rotor torque generated by the square pulse has the greatest variation over the cycle. While the realistic pulse results in the lowest peak torque production, a plateau at the peak occurs, maintaining a constant maximum torque for approximately a third of the cycle. The resulting torque produced by both the sinusoidal and triangular wave forms are very similar, as are the rotor inlet mass flows due to damping of the triangular wave in the volute.

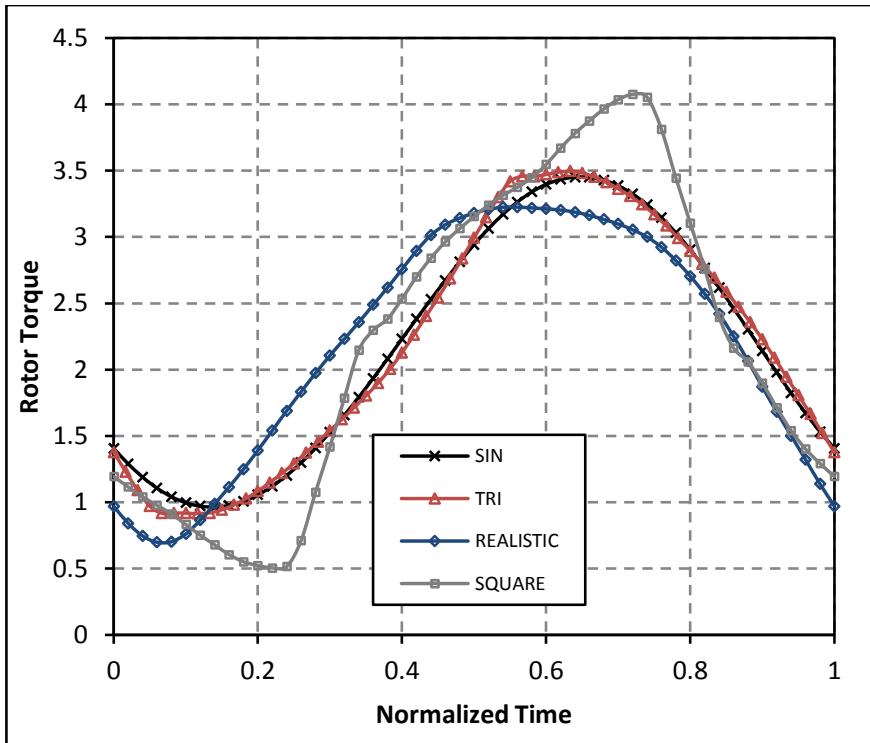

Figure 11 - Instantaneous Rotor Torque for Each Inlet Pulse Shape

Figure 12 shows that the MFP hysteresis of the square pulse is significantly larger than the others with the hysteresis forming a rhomboid shape around the steady state results. Both the sinusoidal and triangular shapes show similar results, but the triangular wave shows a slight increase in hysteresis in localized regions. The realistic wave results in a larger pressure ratio range than the sinusoidal or triangular pulses with the pressure ratio reducing down to 1.4. Furthermore, the MFP hysteresis also shows a significant change in shape at the higher pressures ratios when compared to that of the sinusoidal and triangular waves. The steadily varying mass flow of the sinusoidal wave results in a smaller performance hysteresis than the other wave forms which contain greater rates of change of mass flow.

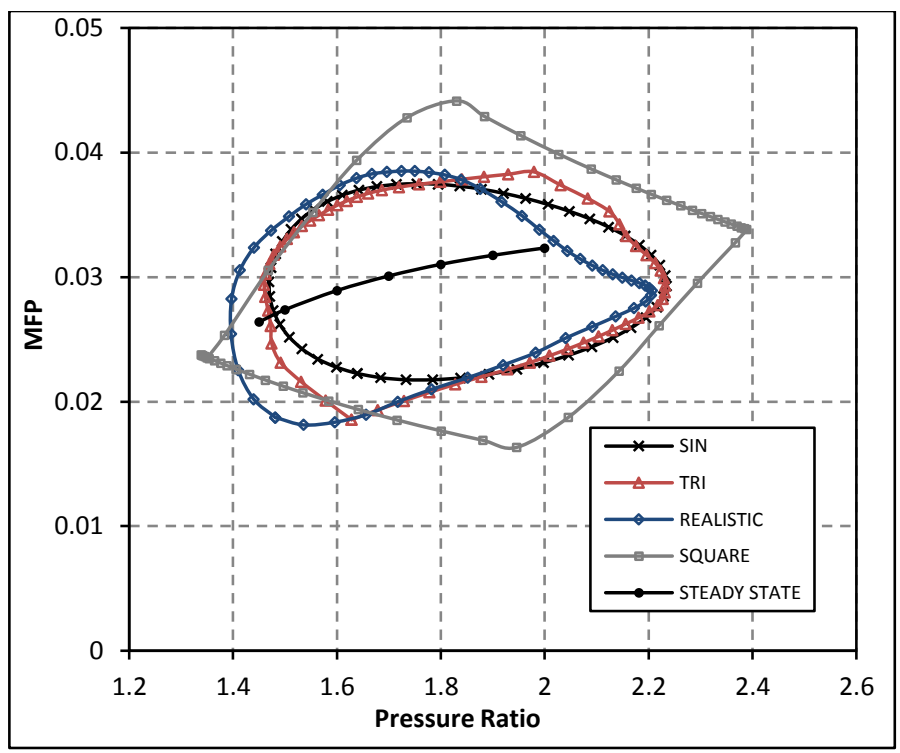

Figure 12 - Instantaneous MFP for Each Inlet Pulse Shape

The resulting instantaneous rotor performance is presented in figure 13 as rotor $U / c_{s}$ against instantaneous rotor efficiency respectively. The rotor $U / c_{s}$ is defined in equation 3 .

$$
U / c_{S}=\frac{U}{\sqrt{2 \cdot C_{p} \cdot T_{02} \cdot\left(1-\left(\frac{P_{3}}{P_{02}}\right)^{\frac{\gamma-1}{\gamma}}\right.}}
$$

Where $U$ is the rotor speed, $C_{p}$ is the specific heat at constant pressure, $T_{02}$ is the total temperature at the rotor inlet, $P_{3}$ is the static pressure at the rotor outlet, $P_{02}$ is the total pressure at the rotor inlet and $\gamma$ is the ratio of specific heats. The instantaneous rotor efficiency is defined in equation 4.

$$
\eta_{\text {rotor }}=\frac{\tau \cdot \omega}{m_{2} \cdot C_{p} \cdot T_{02} \cdot\left(1-\left(\frac{P_{3}}{P_{02}}\right)^{\frac{\gamma-1}{\gamma}}\right.}
$$

Where $\tau$ is rotor torque, $\omega$ is the rotor angular velocity and $\dot{m}_{2}$ is the rotor inlet mass flow.

From figure 13 it is clear that the range of velocity ratios that the blade encounters was greatest under the square inlet wave, with both the maximum and minimum velocity ratio limits extending, resulting in a $U / c_{S}$ range of 0.469 to 0.856 . The realistic wave form also results in an increased maximum velocity ratio achieved when compared to that of the sinusoidal or triangular wave forms. However, the minimum velocity ratio achieved under the realistic pulse is slightly higher than that of the sinusoidal or triangular waves. Both the sinusoidal and triangular waves result in similar velocity ratio ranges which is 
expected as the rotor inlet mass flow pulses were very similar. In all cases, a greater rotor performance hysteresis was seen at higher rotor velocity ratios, with the square wave form exhibiting the greatest hysteresis.

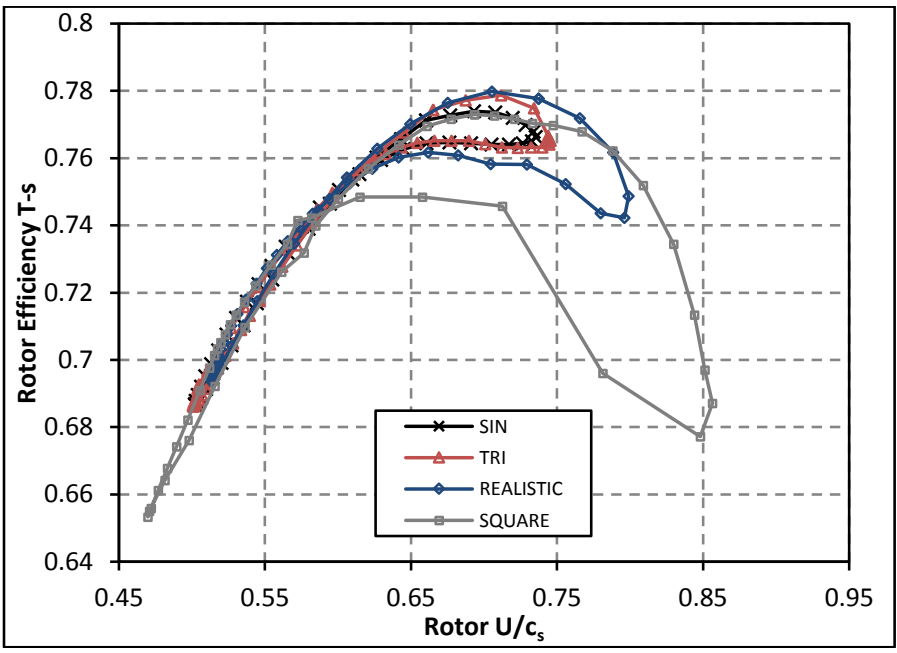

Figure 13 - Instantaneous Rotor Efficiency (T-s) for Each Inlet Pulse Shape

Rotor leading edge incidence has a significant impact on rotor performance and under pulsating conditions incidence varies significantly. Non-optimal incidence is of particular interest at higher velocity ratio running points, where the energy available for extraction is maximized. At these high velocity ratios, incidence becomes increasingly positive resulting in blade suction surface separation. Mixed flow rotors, such as the one used in this study, aim to reduce this loss by introducing a none zero blade angle to combat the positive inflow angles. The resulting variation in rotor leading edge incidence against rotor velocity ratio is presented in figure 14 for all four inlet pulse shapes. As with the efficiency curves, plotted in Figure 13, the sinusoidal and triangular waves result in very similar leading incidence angle distributions with only localized variation at peak incidence. In comparison, the realistic wave reached more negative incidence angles at the higher velocity ratios achieved and the square wave resulted in even greater negative incidence at velocity ratios as high as 0.85 . The peak incidence angle of the realistic wave was the lowest of the four tested, at only $10.6^{\circ}$. The sinusoidal and triangular waves peaked at $11.5^{\circ}$ and $12.5^{\circ}$ respectively. Despite the square wave reaching the lowest velocity ratio, the maximum incidence achieved was only $11.6^{\circ}$ and at the peak incidence angle distribution shows clear deviation from the trends experienced by the other pulse shapes.

In addition, figure 15 presents the variation in leading edge incidence plotted against normalized time. This plot shows how rapidly incidence varies with time over the pulse. In all cases a plateau at maximum incidence occurs resulting in an almost constant value for a significant period of the pulse. At the lowest incidence angles, the variation occurs much more rapidly and no plateau occurs. In the realistic wave case, the peak plateau exists over approximately $40 \%$ of the pulse. Both the sinusoidal and triangular waves result in the lowest rate of change of incidence throughout the pulse and the smallest range in leading edge incidence. On the other hand, the variation in incidence angle occurs much more rapidly under the square wave with the increase in incidence from the minimum to maximum occurring over approximately $10 \%$ of the pulse.

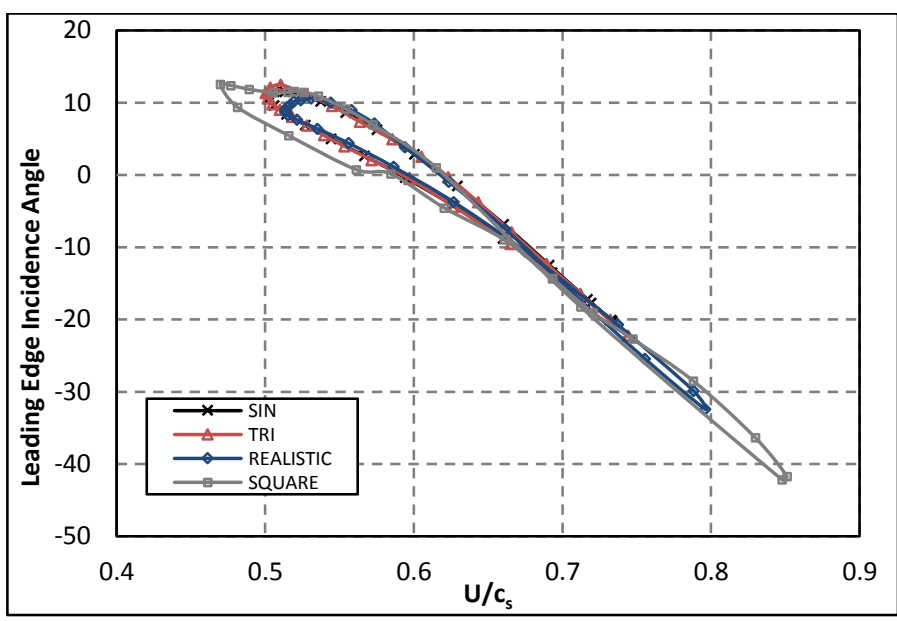

Figure 14 - Change in leading edge incidence plotted against velocity ratio for the four tested inlet pulse shapes.

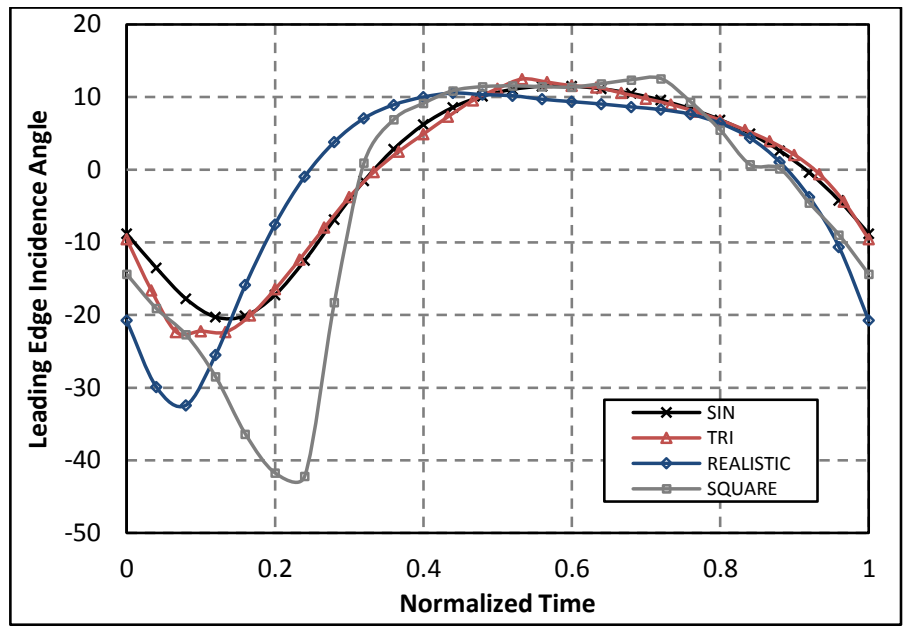

Figure 15 - Change in leading edge incidence over normalized time for the four tested inlet pulse shapes.

Table 1 shows the cycled averaged stage efficiencies and MFP's of the turbine under each of the investigated pulse shapes. The definitions of the cycle averaged efficiency and cycle averaged MFP are presented in equations 5 and 6 respectively.

$$
\eta_{c y c}=\frac{\int_{0}^{T}(\tau \cdot \omega) d t}{\int_{0}^{T}\left(m_{1} \cdot C_{p} \cdot T_{01} \cdot\left(1-\left(\frac{P_{4}}{P_{01}}\right)^{\frac{\gamma-1}{\gamma}}\right)\right) d t}
$$




$$
M F P_{c y c}=\frac{\int_{0}^{T} M F P d t}{T}
$$

Where $\tau$ is rotor torque, $\omega$ is the rotor angular velocity, $\dot{m}_{1}$ is the mass flow at the stage inlet, $C_{p}$ is the specific heat at constant pressure, $T_{01}$ is the total temperature at the stage inlet, $P_{4}$ is the static pressure at the stage outlet, $P_{01}$ is the total pressure at the stage inlet and $\gamma$ is the ratio of specific heats.

In this instance, there is little variation between the sinusoidal, triangular and realistic wave forms in both efficiency and MFP. However, the square wave shows a significant reduction in cycle averaged MFP of $2.33 \%$ and a reduction in efficiency of $1.37 \%$. This result shows that, at least in the cycleaveraged sense, pulse shape only has a small impact on performance.

\begin{tabular}{c|cccc}
\hline & SIN & TRI & Realistic & Square \\
\hline $\begin{array}{c}\text { Normalized } \\
\text { Stage } \boldsymbol{\eta}_{\boldsymbol{c y c}}\end{array}$ & $100.00 \%$ & $99.87 \%$ & $99.74 \%$ & $98.63 \%$ \\
\hline $\begin{array}{c}\text { Normalized } \\
\boldsymbol{M} \boldsymbol{F} \boldsymbol{P}_{\boldsymbol{c y c}}\end{array}$ & $100.00 \%$ & $99.67 \%$ & $99.50 \%$ & $97.77 \%$ \\
\hline
\end{tabular}

Table 1 - Cycle averaged performance results for each pulse normalized by the sinusoidal wave results

\section{CONCLUSIONS}

This work investigated the performance of a mixed flow turbine operating under unsteady pulsating flow conditions. From the four pulse shapes investigated, only the square pulse shows a significant variation in cycle-averaged turbine performance. This deviation can be explained by the change in effective frequency as defined by Szymko [20]. However, the instantaneous performance differs significantly for all pulse shapes. This result shows that while pulse shape only has a small impact on performance in a gross, cycle-averaged sense, it is important with regards to any in-depth analysis of the turbine flow physics. Therefore, a simplified sinusoidal wave form can be used for investigations of global performance trends, but for more detailed studies into the flow physics and loss mechanisms within the pulse, matching the pulse shape is vital.

The work presented is part of an ongoing study into turbine pulse flow performance and further work is underway to fully characterize the impact of pulse, shape, frequency and amplitude on turbine performance and loss mechanisms.

\section{NOMENCLATURE}

$\begin{array}{ll}\text { CFD } & \text { Computational Fluid Dynamics } \\ C_{p} & \text { Specific Heat at Constant Pressure } \\ \text { MFP } & \text { Mass Flow Parameter } \\ M_{a c c} & \text { Mass accumulation (-) }\end{array}$

$\begin{array}{ll}\dot{m} & \text { Mass Flow }(\mathrm{kg} / \mathrm{s}) \\ \eta & \text { Efficiency }(\%) \\ P & \text { Static Pressure }(\mathrm{Pa}) \\ P_{0} & \text { Total Pressure }(\mathrm{Pa}) \\ \text { RMS } & \text { Root Mean Squared } \\ \mathrm{SST} & \text { Shear Stress Transport } \\ T_{0} & \text { Total Temperature }(\mathrm{K}) \\ \mathrm{T}-\mathrm{s} & \text { Total-to-static } \\ \tau & \text { Torque }(\text { Nm) } \\ U & \text { Blade Speed (m/s) } \\ U / c_{S} & \text { Velocity Ratio }(-) \\ \gamma & \text { Ratio of Specific Heats } \\ \omega & \text { Angular Velocity }(\mathrm{m} / \mathrm{s})\end{array}$

Subscripts

$\begin{array}{ll}1 & \text { Turbine Inlet } \\ 2 & \text { Rotor Inlet } \\ 3 & \text { Rotor Outlet }\end{array}$

\section{ACKNOWLEDGMENTS}

The authors would like to thank BorgWarner Turbo Systems for their support throughout this project.

\section{REFERENCES}

[1] Wallace, F. and Blair, G. The pulsating-flow performance of inward radial-flow turbines. in ASME 1965 Gas Turbine Conference and Products Show. 1965. American Society of Mechanical Engineers.

[2] Newton, P.J., An Experimental and Computational Study of Pulsating Flow within a Double Entry Turbine with Different Nozzle Settings, in Department of Mechanical Engineering. 2013, Imperial College London.

[3] Benson, R.S. and Scrimshaw, K.H., An Experimental Investigation of Non-Steady Flow in a Radial Gas Turbine. Proc Instn Mech Engrs, 1965. 180 (10).

[4] Kosuge, H., Yamanaka, N., Ariga, I., and Watanabe, I. Performance of radial flow turbines under pulsating flow conditions. in American Society of Mechanical Engineers, Gas Turbine Conference and Products Show, Houston, Tex. 1975.

[5] Benson, R.S., Nonsteady flow in a turbocharger nozzleless radial gas turbine. 1974, SAE Technical Paper.

[6] Dale, A. and Watson, N., Vaneless radial turbocharger turbine performance IMechE Paper no. C110, 1986. 86.

[7] Szymko, S., Martinez-Botas, R., and Pullen, K. Experimental evaluation of turbocharger turbine performance under pulsating flow conditions. in ASME Turbo Expo 2005: 
Power for Land, Sea, and Air. 2005. American Society of Mechanical Engineers.

[8] Padzillah, M., Rajoo, S., Yang, M., and Martinez-Botas, R., Influence of pulsating flow frequencies towards the flow angle distributions of an automotive turbocharger mixedflow turbine. Energy Conversion and Management, 2015. 98: p. 449-462.

[9] Galindo, J., Fajardo, P., Navarro, R., and García-Cuevas, L.M., Characterization of a radial turbocharger turbine in pulsating flow by means of CFD and its application to engine modeling. Applied Energy, 2013. 103: p. 116-127.

[10] Galindo, J.F., P; Navarro, Garcia-Cuevas, L; Characterization of a Radial Turbocharger Turbine in Pulsating Flow by Means of CFD and its Application to Engine Modeling Applied Energy, 2013.

[11] Lee, S., Jupp, M., and Nickson, A. The influence of secondary flow structures in a turbocharger turbine housing in steady state and pulsating flow conditions. in Mechanical and Aerospace Engineering (ICMAE), 2016 7th International Conference on. 2016. IEEE.

[12] Costall, A. and Martinez-Botas, R.F. Fundamental characterization of turbocharger turbine unsteady flow behavior. in ASME Turbo Expo 2007: Power for Land, Sea, and Air. 2007. American Society of Mechanical Engineers.

[13] Roclawski, H., Gugau, M., Langecker, F., and Böhle, M. Influence of Degree of Reaction on Turbine Performance for Pulsating Flow Conditions. in ASME Turbo Expo 2014: Turbine Technical Conference and Exposition. 2014. American Society of Mechanical Engineers.

[14] Hellstrom, F. and Fuchs, L., Numerical computation of the pulsatile flow in a turbocharger with realistic inflow conditions from an exhaust manifold. ASME, 2009.

[15] Yang, M., Martinez-Botas, R., Rajoo, S., Yokoyama, T., and Ibaraki, S., Influence of Volute Cross-Sectional Shape of a Nozzleless Turbocharger Under Pulsating Flow Condition ASME Turbo Expo, 2014.

[16] Hakeem, I., Su, C.C., Costall, A., and Martinez-Botas, R., Effect of volute geometry on the steady and unsteady performance of mixed-flow turbines. Proceedings of the Institution of Mechanical Engineers, Part A: Journal of Power and Energy, 2007. 221(4): p. 535-549.

[17] Galindo, J., Hoyas, S., Fajardo, P., and R, N., Set-up Analysis and Optimisation of CFD Simulations for Radial Turbines. Engineering Application of Computational Fluid Mechanics, 2014.

[18] Aymanns, R., Scharf, J., Uhlmann, T., and Luckmann, D., A Revision of Quasi Steady State Modeling of Turbocharger Turbines in the Simulation of Pulse Charged Engines. Aufladetechnische Konferenz Dresden, 2011.

[19] Zimmermann, R., Baar, R., Enghardt, L., and Hakensson, S., Investigation on Pulsating Turbine Flow Radial Turbines. Aachen Colloquium Automobile and Engine Technology, 2015.

[20] Szymko, S., The development of an eddy current dynamometer for evaluation of steady and pulsating turbocharger turbine performance,". 2006, Imperial College.

S. P. Lee was born in the United Kingdom. He received his MSc in aerodynamics from Cranfield University UK in 2014. He is currently a PhD student in the Turbocharger Research Institute at the University of Huddersfield. His work focuses on aerodynamic optimization of mixed flow turbines for turbocharger applications.

A. Rezk was Born in Egypt. He received his BSc in mechanical engineering from Alexandria University Egypt and $\mathrm{PhD}$ in thermofluids from Birmingham University UK. He is currently a post-doctoral research in the Turbocharger Research Institute at the University of Huddersfield

M. L. Jupp was born in the United Kingdom. He received his BEng in mechanical engineering from De Montfort University $\mathrm{UK}$ and $\mathrm{PhD}$ in aerodynamics from Glasgow University UK. He is currently a Principle Enterprise Fellow in the Turbocharger Research Institute at the University of Huddersfield

A. K. Nickson was born in the United Kingdom. He received his BEng in mechanical engineering and $\mathrm{PhD}$ in non-Newtonian fluid mechanics from Liverpool University UK. He is currently a Staff Performance Engineer at BorgWarner Turbo Systems. 